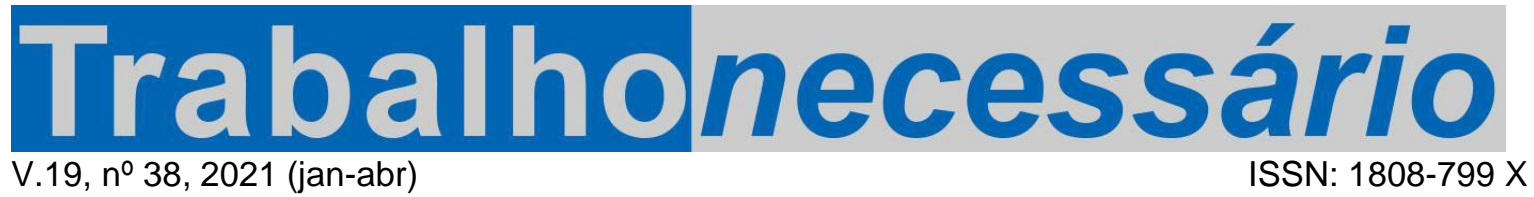

\title{
QUEM AMA NÃO MATA - É PRECISO VOLTAR ÀS RUAS ${ }^{1}$
}

Leila de Andrade Linhares Barsted²

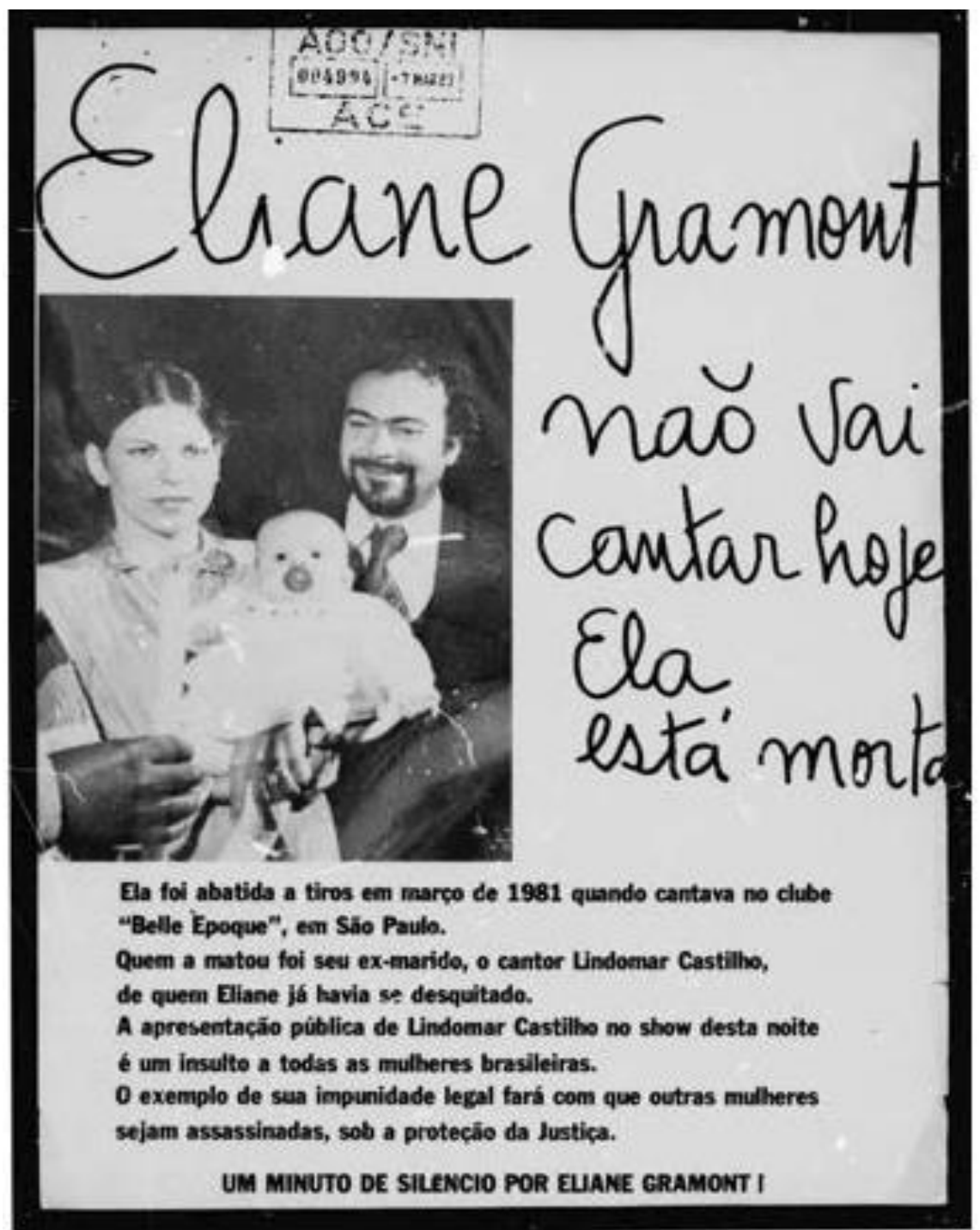

Sāo Paulo, repudio das feministas a li berdade do assassino de Eliane de Gramont

1 Texto recebido em 14/12/2020. Aprovado pelos editores em 15/12/2020. Publicado em 25/2021. DOl: https://doi.org/10.22409/tn.v19138.47625

2 Advogada, Membro do Comitê de Especialistas do MESECVI - Mecanismo de Monitoramento da Convenção para Prevenir, Punir e Erradicar a Violência contra das Mulheres da Organização dos Estados Americanos - OEA. Professora Emérita da Escola de Magistratura do Estado do Rio de Janeiro, Coordenadora Executiva da CEPIA. 
Esse texto tem como objetivo resgatar o percurso do movimento feminista no enfrentamento da violência de gênero contra as mulheres, em especial no que se refere à refutação do argumento da legítima defesa da honra.

Há 40 anos era comum no Brasil a absolvição de homens que assassinavam suas mulheres, crimes que, desde 2015 são considerados feminicídios. De fato, até meados da década de 1970, o argumento da "legítima defesa da honra" era comumente aceito pelo Tribunal do Júri ${ }^{3}$ para deixar de punir acusados de terem assassinado suas mulheres ou companheiras, apesar de não haver na legislação brasileira a pena de morte. Esse era um direito previsto na lei no período do Império ${ }^{4}$ e, mesmo abolido posteriormente, manteve-se na cultura, fortalecido pela Código Civil de 1916 que considerava o homem como chefe da família ${ }^{5}$ e restringia um conjunto de direitos de cidadania para as mulheres ${ }^{6}$.

$\mathrm{O}$ argumento da legítima defesa da honra vinha acompanhado da acusação contra a vítima. De fato, a defesa dos autores de assassinatos sustentava-se na caracterização do crime como um "crime de amor" provocado pelo comportamento da vítima e pelo seu desejo de quebrar as algemas ${ }^{7}$. Assim, os jurados, na realidade, acabavam julgando o comportamento das mulheres e não o do seu agressor. Expressões e adjetivações humilhantes, como adúlteras, traidoras, messalinas, diabólicas, relapsas no cuidado com a família e com os filhos, eram usadas pelos advogados de defesa para caracterizá-las como agentes provocadoras de homens honestos, bons chefes de família, trabalhadores que, sem outra alternativa, praticavam o crime.

Esses foram os argumentos para absolver os assassinos de Angela Diniz, morta em 1976, no Rio de Janeiro; de Heloisa Ballesteros, morta em 1976, e Maria Regina Souza Rocha, morta em 1980, ambas em Belo Horizonte; de Cristhel Arvid Johnston, morta em 1978, no Rio de Janeiro; de Eliane de Grammont, morta em1981, em São Paulo. Todos os acusados foram praticamente absolvidos por serem primários e de bons antecedentes. No primeiro julgamento do assassino de Angela Diniz, realizado na cidade de Cabo Frio, no Rio de Janeiro, esses mesmos

\footnotetext{
${ }^{3}$ O Tribunal do Júri é formado por sete juízes leigos, cidadãos comuns, que julgam os chamados crimes dolosos contra a vida e, certamente, decidem de acordo com seus valores e possíveis preconceitos.

${ }^{4}$ Ver a esse respeito HERMANN, Jacqueline e BARSTED, Leila Linhares (1995).

${ }^{5}$ Cf BARSTED, Leila Linhares e GARCEZ, Elizabeth (1999).

${ }^{6}$ Sobre legítima defesa da honra, ver PIMENTEL, Silvia; PANDJIARJIAN, Valéria. BELLOQUE, Juliana (2006)

${ }^{7}$ Cf. ALMEIDA, Suely (1998).
} 
argumentos foram utilizados. Tanto a absolvição do réu como o aviltamento da vítima recrudesceram as manifestações feministas.

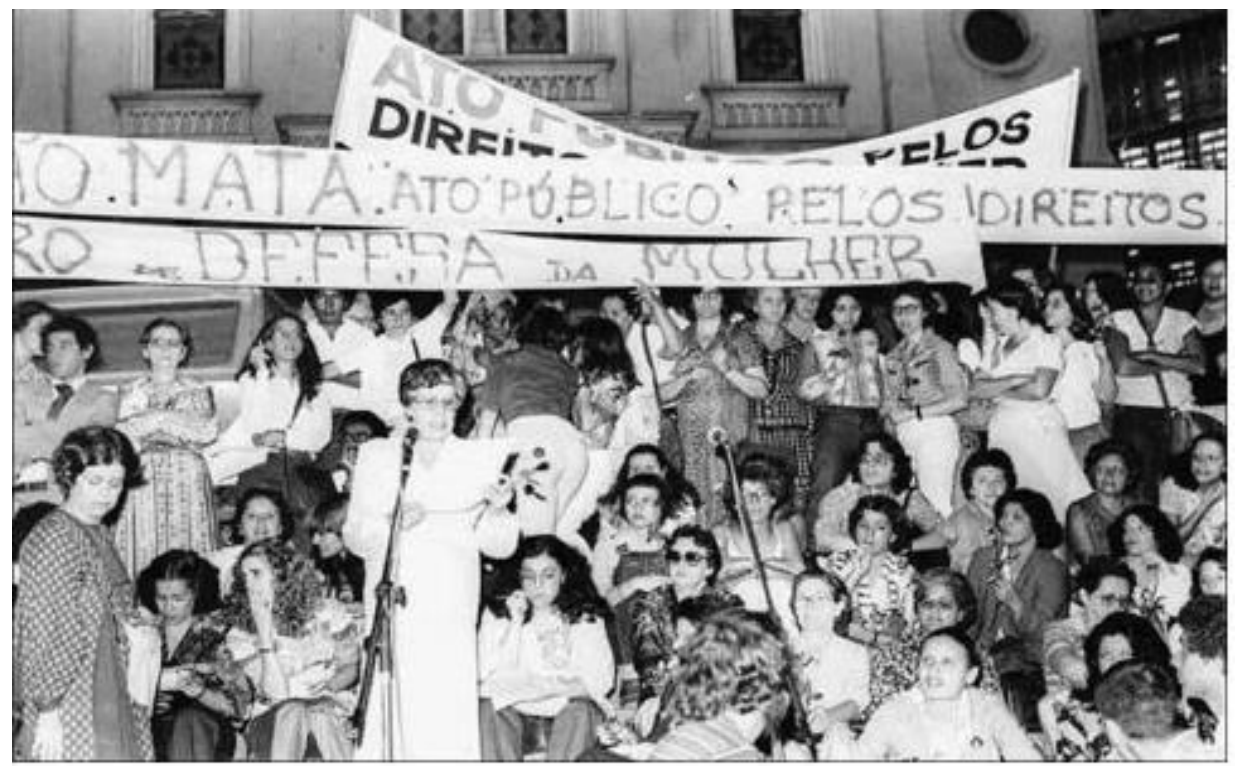

Manifestaçāo fem inista em fren te a lgreja de Sāo Jose, em Belo Horizonte, 1980

Em 1981, grande manifestação reuniu centenas de mulheres, diante da Igreja de São José, no centro de Belo Horizonte, que exibiam as faixas e cartazes com a bandeira que se tornaria o símbolo da luta do novo feminismo que se anunciava no Brasil - "quem ama não mata".

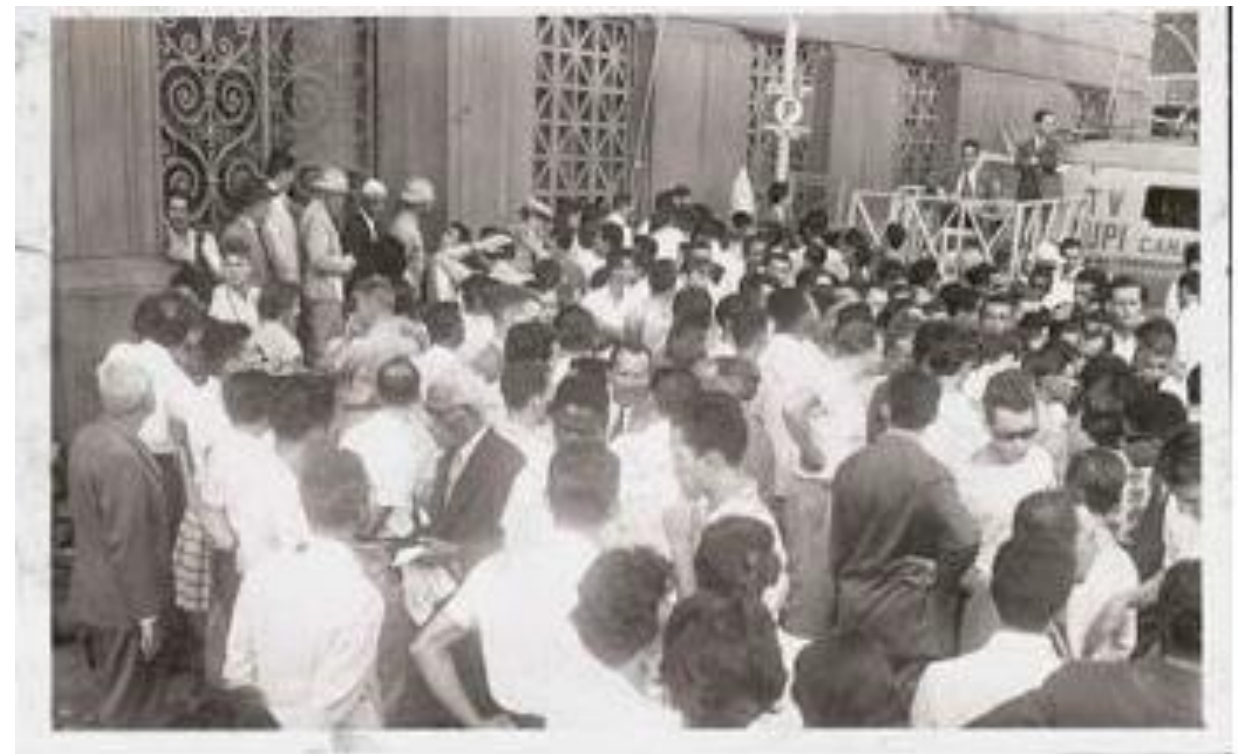

Forum de Cabo Frio, primeiro julgamento do assassino de Angela Diniz 
No Rio de Janeiro, depois da absolvição do assassino de Angela Diniz, as feministas se mobilizaram defendendo a anulação da decisão do Júri Popular. Em segundo julgamento, foram mais uma vez para as ruas e fizeram vigília em frente do Fórum de Cabo Frio durante o julgamento. A condenação do réu, Doca Street, em 1981, representou a vitória não só do advogado da família de Angela Diniz. Em entrevista, o criminalista Heleno Fragoso reconheceu que a sua vitória, em muito foi possível graças à mobilização das feministas. Os chamados "crimes da paixão" ou "crimes passionais" passaram a ser considerados crimes de ódio. É importante destacar que as mulheres anônimas, negras e pobres assassinadas por seus maridos e companheiros continuavam sem visibilidade na grande imprensa ${ }^{8}$.

As manifestações dos movimentos feministas se espalharam rapidamente e, entre 1975 e 1985 existia, em quase todos os estados brasileiros, grupos de mulheres que ecoaram a necessidade de uma militância ativa na denúncia das diversas formas de discriminação, contra a violência de gênero na sociedade e no Estado ${ }^{9}$. Em paralelo à mobilização contra esses crimes, grupos feministas criaram os SOS Mulher para atender as vítimas de violência, prestando orientação e apoio ${ }^{10}$.

A denúncia da violência contra as mulheres incluía também a denúncia da legislação civil que mantinha dispositivos claramente discriminatórios. O espaço da família, regido, até 1988, pelo Código Civil de 1916, legitimava o poder do marido sobre a mulher e permitia a manutenção de uma cultura de violência nas relações entre os cônjuges, naturalizada como um simples conflito familiar a ser tratado na esfera estritamente privada.

Todo o início da década de 1980 foi marcado pela distensão política, e grandes manifestações de setores progressistas, com a expressiva participação de mulheres, exigiam a redemocratização do país. Esse processo político permitiu, em 1982, a eleição livre para governadores de estados, com a vitória de Franco Montoro, em São Paulo, Tancredo Neves, em Minas Gerais, e Leonel Brizola no Rio de Janeiro. Nesses três estados, em especial em São Paulo, muitas feministas conseguiram a criação dos

\footnotetext{
${ }^{8}$ Sobre sexismo e racismo ver CARNEIRO, Sueli (2011)

${ }^{9}$ A violência política do Estado contra as mulheres foi especialmente destacada, em 2013, quando a Comissão Nacional da Verdade - CNV colheu relatos de mulheres que foram submetidas à prisão, tortura, estupros e assassinato durante a ditadura militar. Também, a Anistia Internacional tem apontado a violência contra mulheres no sistema prisional cometida por agentes do Estado.

${ }_{10}$ Ver a esse respeito SORJ, Bila; MONTERO, Paula (1985).
} 
primeiros Conselhos Estaduais da Condição Feminina, de Delegacias de Mulheres e de abrigos para mulheres em situação de risco de vida.

Data marcante para a democracia e para os movimentos feministas foi 1985. Nesse ano, com a eleição indireta para a presidência da república, deu-se a concretização do retorno à democracia política com a posse de um presidente civil que reconheceu o compromisso assumido com as feministas e criou o Conselho Nacional dos Direitos das Mulheres - CNDM, que, no período de 1985-1989 inaugurou a inclusão de uma agenda feminista no cenário político nacional com histórico impacto no texto da nova Constituição de 1988. A atuação do $\mathrm{CNDM}^{11}$ colocou como questão de Estado as demandas dos movimentos de mulheres que, posteriormente, foram consolidadas na "Carta das Mulheres Brasileiras aos Constituintes" (anexada ao final do texto) e entregue ao Presidente do Congresso Nacional Ulisses Guimarães. Dentre as inúmeras demandas aprovadas no texto da Constituição Federal de 1988 foi incluído o enfrentamento da violência familiar"12. Em publicação do CNDM "Quando a Vítima é Mulher"13 e com a divulgação pelo IBGE dos resultados da PNAD ${ }^{14}$, de 1988, ficaram explicitadas estatisticamente as características de gênero desse fenômeno: o principal lócus de ocorrência de violência para os homens era a rua, o espaço público e, para as mulheres, era a casa, o espaço privado. A pesquisa do CNDM revelava, assim, que as violências contra as mulheres eram praticadas por pessoas que privavam da intimidade da vítima, em geral maridos e companheiros. Esse padrão se mantém até os nossos dias.

Muitos foram os avanços a partir de então na luta contra a violência de gênero ${ }^{15}$ contra as mulheres, nas suas diversas manifestações. Na década de 1990, formaramse as redes e organizações feministas em todo o país, potencializando a defesa dos direitos das mulheres e a luta contra a violência e o uso do argumento da legítima defesa da honra. Essa atuação dos movimentos feministas ecoou no Superior Tribunal de Justiça que, em 1991, rejeitou a legítima defesa da honra. Em 1993, a Declaração da Conferência de Direitos Humanos das Nações Unidas, fortaleceu a luta feminista ao definir que "a violência contra as mulheres é uma violação de Direitos Humanos".

\footnotetext{
11 Sobre a atuação do CNDM ver PITANGUY, Jacqueline (2008) e SCHUMAHER, S. (2008).

${ }^{12}$ Artigo 226, § 8o - O Estado assegurará a assistência à família na pessoa de cada um dos que a integram, criando mecanismos para coibir a violência no âmbito de suas relações.

${ }^{13}$ ARDAILLON, Danielle (1987).

${ }^{14}$ IBGE/PNAD - Suplemento sobre Justiça e Vitimização, 1988

${ }^{15}$ Sobre o conceito de violência de gênero ver SAFFIOTI, Heleieth. Contribuições feministas para o estudo da violência de gênero disponível em https://www.scielo.br/pdf/cpa/n16/n16a07.pdf.
} 
Em 1994, a Organização dos Estados Americanos - OEA, aprovou a Convenção para Prevenir, Punir e Erradicar a Violência contra as Mulheres - Convenção de Belém do Pará. Na década de 2000, as operadoras do direito de ONGs feministas e de outras instituições atuaram de forma decisiva, sob a forma de um consórcio, na elaboração do texto que deu origem à Lei Maria da Penha ${ }^{16}$, de 2006. Em 2015 foi aprovada a alteração do Código Penal para incluir o crime de feminicídio. Nessas décadas foram ampliadas as Delegacias de Mulheres, abrigos, centros de referência, núcleos da defensoria pública, juizados de violência doméstica. No entanto, houve pouco investimento em ações de prevenção de todas as formas de discriminação e violência contra as mulheres, incluindo ações voltadas para a mudança de mentalidades e de padrões de comportamento sexistas ainda calcados na dominação patriarcal. Da mesma forma, não se investiu o suficiente para democratizar as instituições de segurança e justiça, com a perspectiva de gênero e étnico-racial, tendo por preocupação o acolhimento e o acesso das mulheres nesses espaços.

Por outro lado, a partir de 2016, iniciou-se o esvaziamento de políticas públicas voltadas para a resposta à violência contra as mulheres. O Estado, e os grupos que nele estão representados ${ }^{17}$, se afastaram com enorme rapidez do pactuado com os movimentos feministas. Ressurge, com força, uma ideologia familista, tal como a do Código Civil de 1916, com rígidos papéis sociais nas relações conjugais expressos em uma espécie de contrato de submissão das mulheres ${ }^{18}$. Além disso, grupos conservadores promovem alterações em Leis Orgânicas de diversos municípios brasileiros para proibir a discussão das questões de gênero no sistema de ensino, e que, positivamente, têm sido rejeitadas pelo Supremo Tribunal Federal.

Da mesma forma, a magnitude da violência contra as mulheres, em especial nas relações interpessoais, revela o quanto a vida privada não se democratizou. Os índices de violência de gênero contra as mulheres, incluindo o de feminicídio íntimo, são extremamente altos, conforme dados do IPEA. E mais preocupante ainda é a retomada do argumento da legítima defesa da honra. O Júri Popular continua absolvendo ou condenando a penas mínimas homens que assassinaram suas mulheres alegando esse argumento. Quando o Ministério Público e os advogados das

\footnotetext{
${ }^{16}$ Sobre o processo de elaboração dessa lei pelas feministas ver CAMPOS, Carmen (org) 2011.

17 Junte-se a isso a liberação de armas, os discursos antidemocráticos, sexistas, racistas e homofóbicos.

${ }^{18}$ A esse respeito ver PATEMAN, Carole (1993) e BOURDIEU, Pierre (1999).
} 
famílias das vítimas chegam a recorrer ao Superior Tribunal de Justiça - STJ, esse órgão do Poder Judiciário tem rejeitado o argumento da legítima defesa da honra e determinado a realização de novo julgamento, mas nem todos recorrem. Em uma posição considerada firme, o Ministro do STJ, Rogerio Schietti Cruz, rejeitou recurso de homem denunciado por tentar matar a esposa e foi claro ao destacar que, desde 1991, o STJ rejeita, com veemência, a tese de legítima defesa da honra e que "....Em um país que registrou, em 2018, a quantidade de 1.206 mulheres vítimas de feminicídio, soa no mínimo anacrônico alguém ainda sustentar a possibilidade de que se mate uma mulher em nome da honra do seu consorte (...) Não vivemos mais períodos de triste memória, em que réus eram absolvidos em Plenários do Tribunal do Júri com esse tipo de argumentação. Surpreende ver ainda essa tese sustentada por profissionais do direito em uma Corte Superior".

No entanto, retrocessos podem ocorrer com muita velocidade. Em 2020, em um caso de tentativa de feminicídio ocorrido em Minas Gerais, o Tribunal do Júri acolheu a tese da legítima defesa da honra e absolveu o acusado. Em sucessivos graus de apelação, o Ministério Público recorreu ao Supremo Tribunal Federal - STF, para a anulação desse julgamento. Em decisão totalmente oposta à do Superior Tribunal de Justiça, a Primeira Turma do STF, por 3 votos a 2, concedeu um habeas corpus para rejeitar o recurso do Ministério Público pela realização de um novo julgamento, considerando que a decisão do Júri Popular é soberana e que os jurados podem decidir pela absolvição do réu a partir de suas convicções íntimas. Os Ministros Alexandre de Moraes e Luís Roberto Barroso votaram a favor de um novo julgamento e questionaram a legitimidade da argumentação baseada na honra ferida em pleno século XXI. O caso voltará a ser votado no STF. Em Artigo ao Jornal El País, as feministas dirigem-se ao STF exortando essa Corte para que não vire as costas para a longa luta das mulheres contra a impunidade agasalhada na tese da legítima defesa da honra, não esqueça as milhares vítimas de feminicídio no Brasil, não abandone os estándares internacionais reconhecidos há longo tempo pela Constituição Brasileira de $1988^{19}$.

\footnotetext{
${ }^{19}$ Ver PIMENTEL, Silvia, BARSTED, Leila e SEVERI, Fabiana artigo publicado no Jornal EI País 20 de outubro de 2020, disponível em https://cepia.org.br/2020/10/21/defesa-da-honraem-2020-o-stf-naopode-vira
} 
Nesse contexto, os movimentos feministas retomam a bandeira lançada na década de 1970 - Quem ama não mata, num claro movimento de que é preciso voltar às ruas.

\section{Referências}

ALMEIDA, S. Feminicídio: algemas (in)visíveis do público-privado. Rio Janeiro: Ed. Revinter, 1998.

ARDAILLON, D. Quando a vítima é mulher. Brasília, Conselho Nacional dos Direitos da Mulher - CNDM, 1987.

BARSTED, L. L. e GARCEZ, E. "A legislação civil sobre família no Brasil". In: BARSTED, Leila Linhares (org). As mulheres e os direitos civis. Rio de Janeiro: CEPIA, 1999.

BOURDIEU, P. A Dominação Masculina. Rio de Janeiro: Ed. Bertrand Brasil, 1999.

CAMPOS, C.(org). Lei Maria da Penha Comentada em uma Perspectiva JurídicoFeminista. Rio de Janeiro: Ed. Lumen Juris, 2011.

CARNEIRO, S. Racismo, sexismo e desigualdades no Brasil. São Paulo: Editora Selo Negro, 2011.

HERMANN, J. e BARSTED, L. L. O Judiciário e a Violência contra a mulher: A ordem legal e a (des) ordem familiar. Rio de Janeiro: CEPIA, 1995.

PATEMAN, C. O Contrato Sexual. Rio de Janeiro: Ed. Paz e Terra, 1993.

PIMENTEL, S.; PANDJIARJIAN, V; BELLOQUE, J. "Legítima Defesa da Honra" llegítima impunidade de assassinos. Um estudo crítico da legislação e jurisprudência da América Latina. In: CORRÊA, M; SOUZA, É. R. de (org.). Vida em família: uma perspectiva comparativa sobre "crimes de honra". Campinas: Editora da Unicamp, p. 65-134, 2006.

PITANGUY, J. As mulheres e a Constituição de 1988. Cadernos de Crítica Feminista, ano 2, oo 1, dez. 2008. Pernambuco: Edições SOS Corpo - Instituto Feminista para a Democracia.

SAFFIOTI, H. Contribuições feministas para o estudo da violência de gênero.

Cadernos Pagu, Campinas: Editora Unicamp, oㅜ 16, pp.115-136, 2001.

SCHUMAHER, S. (2008) O lobby do batom, para dar o nosso tom. Cadernos de Crítica Feminista, ano 2, ㄲo 1, dez. 2008. Pernambuco: Edições SOS Corpo Instituto Feminista para a Democracia. 
SORJ, B; MONTERO, P. O SOS-Mulher e a Luta contra a Violência. In: FRANCHETTO, B; CAVALCANTI, M. L; HEILBORN, M. L. (orgs.). Perspectivas Antropológicas da Mulher. Sobre Mulher e Violência. Rio de Janeiro, Zahar Editores, 1985.

\section{Carta das Mulheres Brasileiras aos Constituintes}

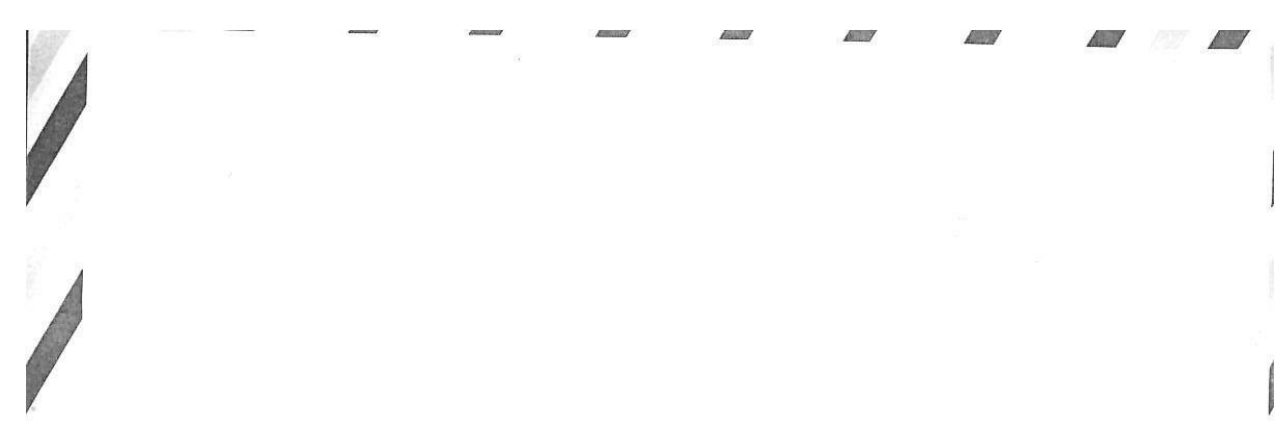

TE: Maria, Ana, Lana, Amparo, Paimunda, Vera, Sônia, Carla, Francisca, Patricia, Marcia, Jimone, Ma de Fatimea, Nausa, Teresa, Concrisão, Socovro, Fucla, Angela, Cristina, Valeiria, Lelma, Cremilda, Rosa, Carmem, Eliana, Marisa, Cecilia, Regina... nós, Mulheres Brasileiras.
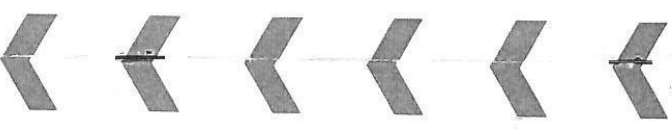

CNDM -

Nacional dos

Direitos da 1

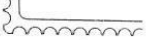

Los Constituintes de 1987

1

Assembleia Pacional Constituinte

Congresso Pacional

Brasilia-DF. 


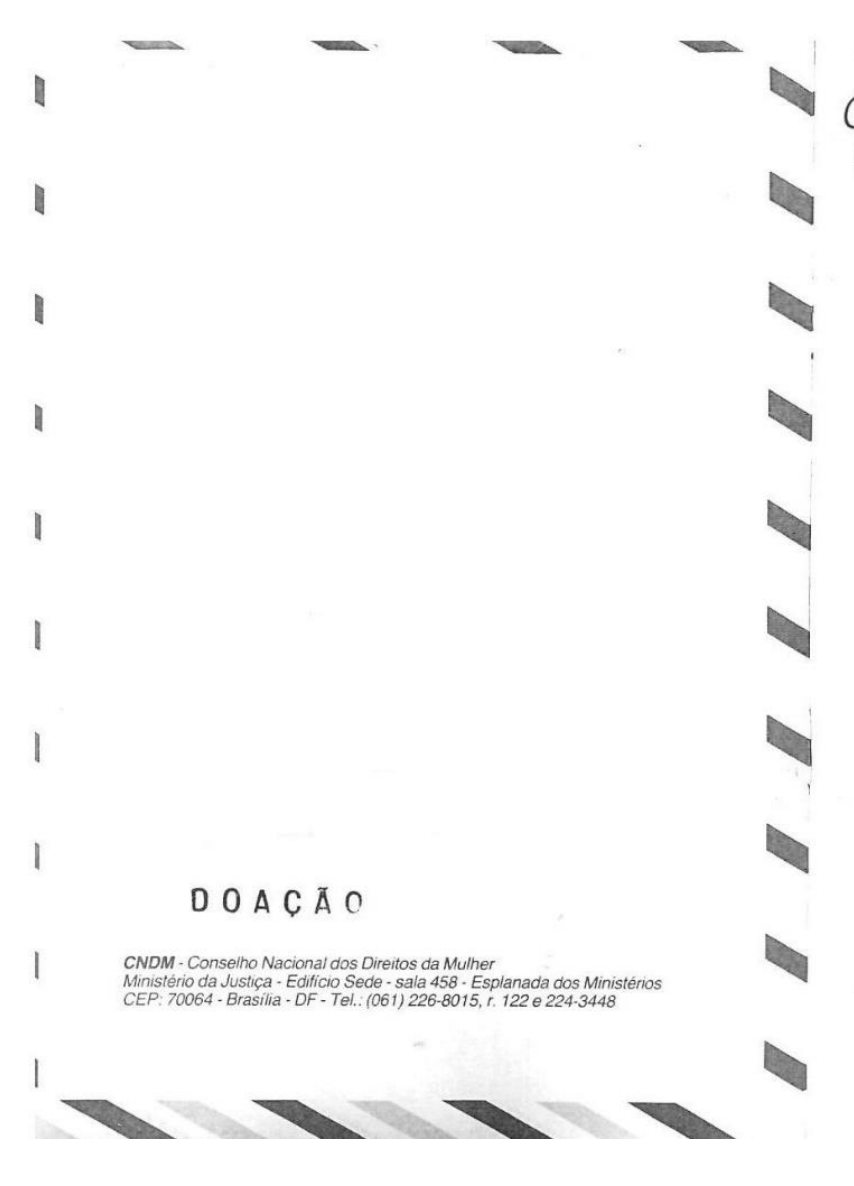

Carta das o conselho Nacional dos Direitos da Muluer, em Mulheres $\begin{aligned} & \text { novstituinte. Desde entaio, o CNDM percorrend a pais. } \\ & \text { ouviu as mulheres brasileiras e ampliou os canais }\end{aligned}$ de comunicação entre o movimento social e os mecanismos de decisão política, buscando fontes de inspiraçâo para a nova legalidade que se quer agora. Nessa Campanha, uma certeza consolidou-se: DE MULHER.

Para nós, mulheres, o exercicio pleno da cidadania significa, sim, o direito à representação, à voz e à vez na vida pública, mas implica, ao mesmo tempo, a dignidade na vida cotidiana, que a lei pode inspirar e deve assegurar, o direito à educação, à saude, a segurança, a vivencia familiar sem traumas. O voto das mulheres traz consigo essa dupla exigência: um sistema politico igualitário e uma vida Nós, autoritaria.

Nos, muheres, estamos conscientes que este pais o será ve cidada verde democratico e seus sem prejuizo de sexo, raça, cor, classe, orientaçấo sexual, credo político ou religioso, condição fisica ou idade, for garantido igual tratamento e igual oportunidade de acesso às ruas, palanques, oficinas, fabricas, escritorios, assembléias e palácios. Nesse importante momento, em que toda a seus ordenamentos, gostariamos de lembrar, para que não se repita, o que mulheres já disseram no passado: "Se nầ for dada a devida atençấo às mulheres. estamos decididas a fomentar uma rebeliāo. e não nos sentiremos obrigadas a cumprir leis para as quais não tivemos voz nem representação (Abigail Adams, 1776).

Hoje, dois séculos após estas palavras, no momento em que a sociedade brasileira se volta para a elaboração de uma nova Constituição, nós, mulheres, maiorimas traConfiamos que os constituintes brasileiros, ulheres e homens, sobre os quais pesa a grande responsabilidade de refletir as aspiraçóes de um povo sofrido e ansioso por melhores condiçôes de vida, incorporem as propostas desta historica Campanha do Conselho Nacional dos Direitos da Mulher.

Eis o que nós, mulheres, reunidas num Encontro Nacional, no dia 26 de agosto de 1986 , queremos:

\section{I - Princípios gerais}

Para a efetivação do princípio de igualdad é fundamental que a futura Constituiçăo Brasileira:

1 - Estabeleça preceito que revogue automaticamente todas as disposiçōes legais que impliquem em classificaçōes discriminatórias:

2 - Determine que a afronta ao princípio de igualdade constituirá crime inafiançável;

3 - Acate, sem reservas, as convençōes e tratados internacionais de que o pais é signatário no que diz respeito à eliminação de todas as formas de discriminação;

4- O reconhecimento da titularidade do direito de açâo aos movimentos sociais organizados, sindicatos, associaçóes e entidades da sociedade civil, na defesa dos interesses coletivos

Leis complementares e demais normas deverão garantir a aplicabilidade desse princípio.

\section{II - Reivindicações específicas}

Familia

A nova Constituição deverá inspirar diversas mudanças na legislação civil, estabelecendo:

1 - A plena igualdade entre os cônjuges no que diz respeito aos direitos e deveres quanto à direção da sociedade conjugal, à administração dos bens do casal, à responsabilidade em relação aos filhos, à fixação do domicílio da família, ao pátrio poder:

2 - A plena igualdade entre o casal no que concerne ao registro de filhos:

3 - A plena igualdade entre os filhos nâo importando o vínculo existente entre os pais;

4 - A proteção da família, seja ela instituída civil ou naturalmente

5 - Acesso da mulher rural à titularidade de terras em civil;

- A maternidade e a paternidade constituem valores sociais fundamentais, devendo o Estado assegurar os mecanismos do seu desempenho;

7 - A lei coibirá a violência na constância das relaçōes familiares, bem como o abandono dos filhos menores.

\section{Trabalho}

A legislaçẫo trabalhista usando por base o princípio constitucional de isonomia deve garantir:

1 - Salário igual para trabalho igual;

2 - Igualdade no acesso ao mercado de trabalho e na ascensão profissional;

3 - Extensāo dos direitos trabalhistas e previdenciários de forma plena às empregadas domésticas e às trabalhadoras rurais:

4 - Igualdade de tratamento previdenciário entre homens e mulheres, devendo ser princípio orientador da legislaçāo trabalhista a proteçắo à maternidade e ao aleitamento atraves

- a garantia do emprego à mulher gestante;

- extensâo do direito à creche no local de trabalho e moradia para as crianças de 0 a 6 anos, filhos de mulheres e homens trabalhadores:

5 - Estabilidade para a mulher gestante;

6 - Licença ao pai nos períodos natal e pós-natal;

7 - Licença especial às pessoas no momento da adoçắo, sem prejuizo do emprego e do salário, independentemente da idade do adotado

8 - Proteção à velhice com integralidade salarial em casos de aposentadoria ou pensão por morte

9 - Eliminação do limite de idade para prestação de concursos públicos:

10 - Direito do marido ou companheiro a usufruir dos benefícios previdenciários decorrentes da contribuição da esposa ou companheira;

11 - Extensão dos direitos previdenciários dos trabalhadores urbanos aos trabalhadores rurais, homens e mulheres. 
12 - Direito de aposentadoria especial aos trabalhadores rurais: 50 anos de idade para as mulheres e 55 anos para os homens, bem como aposentadoria por tempo de serviço aos 25 anos para as mulheres e 30 para os homens, com salário integral;

13 - Direito de sindicalização para os funcionários públicos;

14 - Salário família compatível com a realidade, extensivo aos menores de 18 anos.

\section{Saúde}

1. O princípio "a saúde é um direito de todos e dever do Estado ", na especificidade "mulher", deve garantir que as ações de saúde prestadas a população sejam entendidas como atos de co-participação entre todos e o Estado, envolvendo direitos e deveres de ambos.

1.1 - Criação de um Sistema Único de Saúde constituído a partir de uma nova política nacional de saúde e implementado por serviços públicos de saúd coletiva e assistência médica integrados; submetendo-se os servicos privados às diretrizes e controle do Estado; 1.2 - O Sistema Único de Saúde deve ser gerido e fiscalizad jela população organizada, que, através de e fiscalizad Jela população organizada, que, através de sobre Programas $€$ Financiamentos.

2 - Garantia de Assistência Integral à Saúde da Mulher em todas as fases da sua vida independentemente de sua condição biológica de procriadora, através de programas governamentais discutidos, implementados e controlados com a participaçâo das mulheres.

3 - Proibiçăo de toda e qualquer experimentação com mulheres e homens de substâncias, drogas, meios anticoncepcionais que atentem contra a saúde e não sejam de pleno conhecimento dos usuários nem fiscalizados pelo poder público e a população.

3.1 - Fiscalização da produção, venda, distribuição e comercialização de meios químicos e hormonais de contracepção, proibindo a comercialização de drogas em fase de experimentação por empresas nacionais ou multinacionais.
4 - Garantia a todos os cidadãos, homens e mulheres, contribuintes ou sujeitos de direito, da igualdade de tratamento em todas as açōes da Previdência Social.

5 - Será vedada ao Estado e às entidades nacionais e estrangeiras toda e qualquer ação impositiva que interfira no exercicio da sexualidade. Da mesma forma, sera vedada ao Estado $e$ às entidades nacionais estrangeiras, públicas ou privadas, promover o controle a natalidade.

6 - Será garantido à mulher o direito de conhecer e decidir sobre seu próprio corpo.

7 - Será garantido à mulher o direito de amamentar seus filhos ao seio.

8- O Estado reconhecerá à maternidade e à paternidade relevante função social, garantindo aos pais os meituñocessarios à chça, creche, sa

9 - Garantia de livre opção pela maternidade, compreendendo-se tanto a assistência ao pré-natal, parto e pos-parto, como o direito de evitar ou interromper gravidez sem prejuízo para a saúde da mulher.

10 - É dever do Estado oferecer condições de acesso gratuito aos métodos anticoncepcionais, usando metodologia educativa para esclarecer os resultados, indicações, contra-indicaçōes, vantagens e desvantagens, alargando a possibilidade de escolha adequada à individualidade de cada mulher e, ao momento específico, de sua história de vida.

\section{Educação e Cultura}

1 - A educação, direito de todos e dever do Estado, visa ao pleno desenvolvimento da pessoa, dentro dos

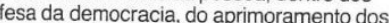
direitos humanos, da liberdade e da convivência solidária

1.1 - A educaçāo dará ênfase à igualdade dos sexos, à luta contra o racismo e todas as formas de discriminação, afirmando as características multiculturais e multirraciais do povo brasileiro:

1.2 - O ensino da história da África e da cultura afro-brasileira deverá ser obrigatório desde a educação básica.

2 - A educacão é prioridade nacional e cabe ao Estado resp insabilizar-se para que seja universal pública, gratuita, em todos os níveis e períodos, desde o primeiro ano da criança.

2.1 - É dever do Estado combater o analfabetismo.

3 - Os recursos públicos deverão destinar-se exclusivamente à escola pública, objetivando a qualidade do ensino, sua expansão manutenção.

3.1 - Cabe ao Estado atenção especial à formaçāo dos agentes da educação e às condiçōes em que exerce o seu trabalho visando à qualidade do ensino.

4 - O Estado deverá dar atenção especial aos alunos portadores de deficiências físicas ou mentais.

5 - Caberá ao Estado garantir o acesso da mulher, rural e urbana, a cursos de formação, reciclagem $e$

6 - É dever do Estado zelar para que a educação e os meios de comunicação estejam a serviço de uma cultura gualitária.

6.1 - O Estado garantirá perante a sociedade a imagem social da mulher, como trabalhadora, māe e cidadā responsável pelos destinos da nação, em igualdade de condiçōes com o homem,

independentemente da origem étnico-racial.

7 - O Estado assegurará a liberdade de pensamento

expressẫo; a liberdade de produçāo, distribuição

divulgação do produto cultural pelos meios de

comunicaçâo social, desde que não veiculem preconceitos

8 - Deverẫo ser incorporados aos estudos e estatísticas oficiais dados relativos a sexo, raça e cor.

\section{Violência}

1- Criminalização de quaisquer atos que envolvam agressōes físicas, psicológicas ou sexuais à mulher, fora e dentro do lar.

2- Consideração do crime sexual como "crime contra pessoa" e nâo como "crime contra os costumes", independentemente de sexo, orientação sexual, raça dade, credo religioso, ocupação, condição física ou mental ou convicçāo política.

3 - Considerar como estupro qualquer ato ou relação sexual forçada, independente do relacionamento do agressor com a vitima, de ser esta última virgem ou nâo e do local em que ocorra.

4 - A lei nāo dará tratamento nem preverá penalidade diferenciados aos crimes de estupro e atentado violento ao pudor.

5 - Será eliminada da lei a expressão "mulher honesta".

6 - Será garantida pelo Estado a assistência médica, jurídica, social e psicológica a todas as vítimas de violência.

7 - Será punido o explorador ou exploradora sexua da mulher e todo aquele que a induzir à prostituição.

8 - Será retirado da lei o crime de adultério.

9 - Será responsabilidade do Estado a criação e manutenção de albergues para mulheres ameaçadas de morte, bem como o auxilio à mua subsistênciaçadas seus filhos.

10 - A comprovaçăo de conjunção carnal em caso de estupro poderá realizar-se mediante laudo emitido por qualquer médico, da rede pública ou privada.

11 - A mulher terá plena autonomia para registrar queixas, independentemente da autorização do marido.

12 - Criação de Delegacias Especializadas no atendimento à mulher em todos os municípios do país,

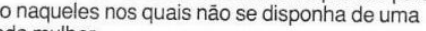

Questões Nacionais e Internacionais

1 - Garantia de integração ao texto constitucional dos Tratados e Convençōes Internacionais, dos quais o Brasi é subscritor, que consagrem os direitos fundamentais, humanos e sociais, entre os quais os que proíbem tratamento discriminatório, com exigibilidade do seu cumprimento.

2 - Reforma agrária com a distribuição de terra aos que nela trabalham, com a garantia de assistência técnica e crédito necessários. 
3 - Soberania na negociação da dívida externa, resguardando os interesses nacionais e do povo brasileiro.

4 - Reforma tributária de forma a beneficiar os municípios.

5 - Liberdade e autonomia sindicais.

$\epsilon$ - Direito de greve extensivo a todas as categorias profissionais.

7 - Política responsável de proteção ao meio ambiente.

8 - Política de desenvolvimento tecnológico com a preservação do meio ambiente e da soberania nacional.

9 - Definição de uma política que mantenha a integridade das populações indígenas, impedindo o genocídio a que vêm sendo submetidas.

10 - Democratização do Estado e das instituições, mediante revogação da Lei de Segurança Nacional e de toda a legislação repressiva.

11 - Acesso às fichas de informação individual mantidas pelos órgãos de informação do governo.

12 - Paz nas relaçôes internacionais, apoio às manifestaçōes contra corrida armamentista e impedimento à experimentação nuclear no Brasil.

13 - Política externa baseada no princípio de autodeterminação dos povos e de não ingerência, vedada qualquer participação em agressões externas, salvo para a defesa do território nacional.

14 - Política de não relacionamento de qualquer espécie com países que praticam o preconceito racial.

15 - Respeito ao princípio de independência entre os três poderes: Legislativo, Executivo e Judiciário, buscando-se o princípio de que todo o poder emana do povo.

CONSTITUINTE PRA VALER TEM QUE TER DIREITOS DA MULHER. 